\title{
Burnout and areas of work-life among anaesthetists in South Africa Part 2: Areas of work-life
}

\author{
JF Coetzee, (1D) H Kluyts²
}

\author{
${ }^{1}$ Department of Anaesthesiology and Critical Care, Faculty of Medicine and Health Sciences, Stellenbosch University, South Africa \\ 2 Department of Anaesthesiology, Dr George Mukhari Academic Hospital, Sefako Makgatho Health Sciences University, South Africa \\ Corresponding author, email:jfc@sun.ac.za
}

Introduction: The purpose of this two-part study was to determine the prevalence and severity of the burnout syndrome among South African anaesthetists working in the public and private sectors, and to identify areas of work-life (AWLs) that predispose to burnout. We reported our burnout findings in Part 1.' In this paper (Part 2) we report on the AWLs.

Methods: Invitations were e-mailed to 1852 SASA members, requesting responses to a validated questionnaire, the Areas of Worklife Survey (Mindgarden Inc. Menlo Park, USA). The questionnaire results in scores for six AWLs that impact on the development of the burnout syndrome, namely workload, control, reward, community, fairness and values.

Results: 189 public sector and 309 private sector anaesthetists responded. 85\% of public sector respondents worked in academic hospitals. The values AWL could not be properly assessed due to respondents' misinterpretations regarding that particular item. Compared to private sector, public sector anaesthetists had lower (i.e. more adverse) median scores for five AWLs. Greater proportions of public sector anaesthetists had low scores for the five AWLs. Correspondingly, smaller proportions of public sector anaesthetists had high (i.e. favourable) scores for workload, control, reward, and fairness.

Multivariable least squares regression analysis identified the following significant explanatory variables for the following burnout dimensions: For emotional exhaustion these were workload, reward, community and control. For cynicism they were workload, reward, control, gender and years of experience. Predictors for efficacy were reward, community, control and years of experience. Logistic regression analysis included workload, reward and control AWL as explanatory variables for a clinical diagnosis of burnout with workload the dominant variable.

Conclusions: Public sector anaesthetists experience more adverse AWLs than those in private practice. The most important factor appears to be excessive workload. Additionally, the reward, community and control AWLs are important determinants of anaesthetists' psychological relationships with their work.

Keywords: burnout-professional, anaesthesiologists-psychology, job satisfaction, work engagement, physician impairment, crosssectional studies

"The experience of burnout is not simply exhaustion resulting from too much work. It reflects a crisis in which employees view the workplace to be at odds with their core values."

Michael Leiter et al., $2010^{2}$

\section{Introduction}

In Part 1 of this study we report on a survey in which we investigated the existence of the burnout syndrome among members of the South African Society of Anaesthetists (SASA). ${ }^{1}$ In that article we concluded that the prevalence and severity of burnout among South African anaesthesia providers were too high, especially among employees in public sector hospitals. In this article (Part 2), we report our findings regarding our simultaneously conducted, parallel survey. The purpose was to identify particular aspects of SASA respondents' personal work experiences that are associated with the three dimensions* of the burnout syndrome, and which may contribute to the development of a clinical diagnosis of burnout. We employed the Areas of Worklife Survey, (Mindgarden Inc. Menlo Park, USA), a validated instrument that assesses the congruence between person and work environment. ${ }^{3}$ This is done by means of a questionnaire that results in scores for each of the six areas of work-life (AWLs) that drive the development of the burnout syndrome. These are workload, control, reward, community, fairness, and values. ${ }^{2-4} \mathrm{~A}$ more detailed description of these six aspects of work-life is given in the Appendix.

The main objectives were to:

1. Compare SASA members' averaged scores for each of the six AWLs with normative values derived from a pre-identified study. ${ }^{3}$

2. Compare scores for each of the six AWLs between anaesthetists working in the public and in the private sector.

3. Identify which AWLs among SASA members are the strongest contributors to the burnout syndrome.

Our hypotheses were that with regard to SASA respondents:

1. Areas of Worklife Scale scores would be more adverse than normative values. 
2. Public sector anaesthetists would return more adverse scores than private practitioners.

3. Excessive workload demands would be the strongest predictors of all three burnout dimensions (emotional exhaustion, cynicism and efficacy).

4. Excessive workload demands would be the strongest predictor for respondents whose burnout scores justify a diagnosis of being clinically burned out, according the "Emotional Exhaustion +1 " principle. ${ }^{+5}$

\section{Methods}

The survey was conducted between July and September 2018. All SASA members with known e-mail addresses were invited to participate by following a link to a web-based questionnaire. The invitation assured anonymity, requested consent, and provided investigator contact details. By responding, participants granted consent for their responses to be used in the study. Responder bias and sensitisation to burnout was limited by excluding the word "burnout" in the invitation and presenting the study as a survey of job-related attitudes.

The Areas of Worklife questionnaire comprises 28 items that produce scores for each of the six AWLs that influence the burnout syndrome: these are workload, control, reward, community, fairness, and values. Each scale includes positively worded items, e.g. "I have enough time to do what's important in my job" (workload) and negatively worded items, e.g. "Favouritism determines how decisions are made at work" (fairness). Respondents indicate their degree of agreement with these statements on a 5-point Likert-type scale ranging from 1 (strongly disagree) to 5 (strongly agree). For each AWL, low scores $(<3)$ indicate possible mismatch between the person and the work environment and high scores ( $>3$ ) indicate congruence.

With regard to the values $A W L$, respondents were asked to identify the two main organisations within which they usually functioned. For anaesthetists working in public hospitals this was the hospital's management, and their anaesthetic department within the hospital. For private practitioners this was the management of the hospitals where they worked and their private practice organisations. Regarding public sector anaesthetists the intention was to determine firstly whether there was a mismatch or congruence between their own value systems and those of the hospital's management, and secondly between themselves and the hospital department within which they functioned. Likewise, regarding private practitioners we intended to determine whether a values congruence or mismatch existed firstly between themselves and the hospitals and secondly between themselves and their practice organisations.

The questionnaire also recorded socio-demographic data: gender, age group, years since qualification, public/private practice and qualification (specialist, trainee, diploma, general practitioner). Completed questionnaires were captured automatically and stored anonymously on a REDCap secure server (https://projectredcap.org/).

\section{Data analysis}

Data were downloaded into an Excel spreadsheet for analysis by statistical software. ${ }^{6,7}$ We estimated the internal consistency of the questionnaire by calculating Cronbach's alpha. ${ }^{8,9}$ We classified participants' scores for the six AWLs into high, moderate, or low categories, according to the scheme depicted in Table I. A low score suggests risk of mismatch between that AWL and the person doing the job.

Table I: Categorisation of scores for the Areas of Worklife Scale ${ }^{3}$

\begin{tabular}{lllll}
\hline \multirow{2}{*}{ Area of Worklife } & \multirow{2}{*}{ Range } & \multicolumn{3}{c}{ Score categories $^{\dagger}$} \\
\cline { 3 - 5 } & & Low & Moderate & High \\
\hline Workload & $<2.33$ & $2.34-3.50$ & $>3.50$ \\
\hline Control & $<2.67$ & $2.67-4.00$ & $>4.00$ \\
\hline Reward & $1-5$ & $<2.75$ & $2.76-3.80$ & $>3.80$ \\
\hline Community & & $<2.80$ & $2.81-4.00$ & $>4.00$ \\
\hline Fairness & & $<2.33$ & $2.34-3.33$ & $>3.33$ \\
\hline Values & & $<2.75$ & $2.76-3.75$ & $>3.75$ \\
\hline
\end{tabular}

+Compiled from a normative study of 22714 individuals from various countries. ${ }^{3}$ Moderate scores range from the 25 th to the 75 th percentile of the normative study. ${ }^{3}$ Low scores are less than the 25 th percentile. High scores are greater than the 75 th percentile.

As in Part 1 of this study, we analysed our questionnaire's scores using a dual approach: firstly, analyses of each of the individual six AWLs, including comparisons with normative scores. ${ }^{3}$ Secondly, we performed regression analyses; a multivariate linear regression analysis, through which we sought predictors of each of the three burnout dimensions as well as logistic regression analysis through which we sought predictors of clinically diagnosable burnout (according to the Emotional Exhaustion+1 principle $^{5}$ ).

Using two-sided t-tests, we compared our sample's mean scores for each of the six AWLs with those from a normative study of $>22500$ employees, which included 15260 hospital workers. ${ }^{3}$ Within-study group data were not normally distributed. Therefore, we compared groups using the Mann-Whitney $U$ test for unpaired data. We accepted an alpha value $<0.05$ as indicating statistical significance. We calculated $95 \%$ confidence intervals $(95 \% \mathrm{Cl})$ for differences between medians according to the Hodges-Lehmann method.10,11 We compared proportional data using the chi-squared test and we calculated $95 \% \mathrm{Cl}$ for proportions according to Wilson's method. ${ }^{10}$ Survey scores derived from Likert scales are not intuitively meaningful. In order to add meaning to the differences between groups, we report appropriate measures of effect-size, namely relative risk for differences between proportions and probability of superiority for the Mann-Whitney $\mathrm{U}$ and Wilcoxon signed rank tests. ${ }^{12}$ (Part 1 Appendix, Tables A1 and A2). ${ }^{1}$

We determined multivariate predictors of the three burnout dimensions $^{\ddagger}$ using stepwise least-squares multiple linear regression. The six AWLs were the continuous independent

† A state of clinically diagnosable burnout is considered to exist when a person has a high Maslach score for emotional exhausion plus either a high score for cynicism or a low score for efficacy.

‡Emotional exhaustion, cynicism and efficacy 
Figure 1: Proportions of respondents with low and high scores for five of the Areas of Worklife
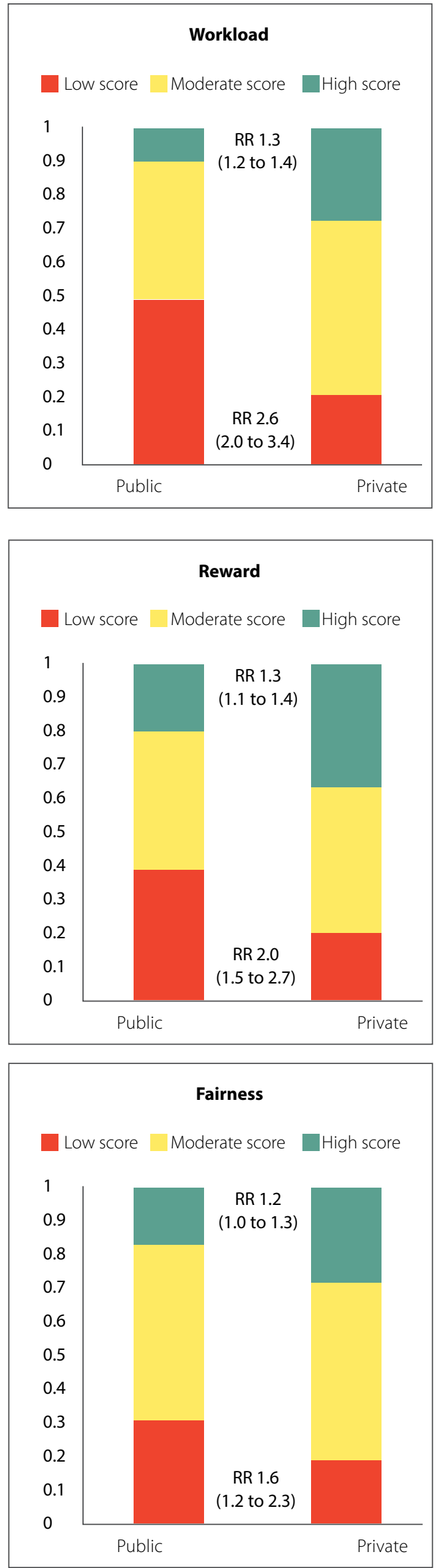
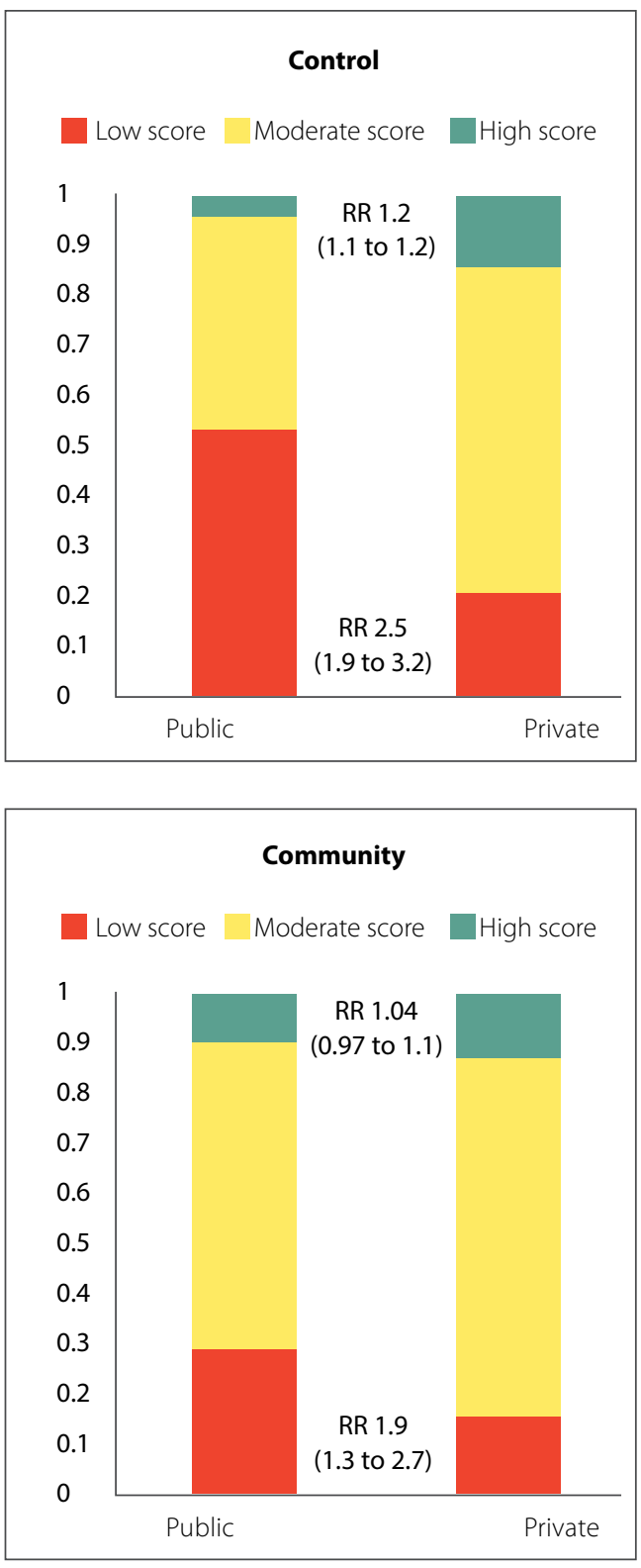

Low scores are adverse and are coloured red. For example a low score for Workload indicates high workplace demands.

Yellow - moderate score

Green - high (i.e. favourable) score

RR - relative risk (95\% confidence interval) 
Table II: Overall, areas of work-life comparisons with results from a normative study ${ }^{3}$

\begin{tabular}{|c|c|c|c|c|c|c|}
\hline Area of work-life & & Mean & SD & 95\% $\mathrm{Cl}$ difference & $p$ & Effect size (Glass's $\Delta$ ) \\
\hline \multirow{2}{*}{ Workload } & SASA & 2.79 & 0.86 & \multirow{2}{*}{0.10 to 0.24} & \multirow{2}{*}{$<0.0001$} & \multirow{2}{*}{0.21 (small) } \\
\hline & Normative & 2.96 & 0.80 & & & \\
\hline \multirow{2}{*}{ Control } & SASA & 3.14 & 0.91 & \multirow{2}{*}{0.09 to 0.23} & \multirow{2}{*}{$<0.0001$} & \multirow{2}{*}{0.20 (small) } \\
\hline & Normative & 3.31 & 0.86 & & & \\
\hline \multirow{2}{*}{ Reward } & SASA & 3.22 & 0.90 & \multirow{2}{*}{-0.11 to 0.05} & \multirow{2}{*}{0.457} & \multirow{2}{*}{0.03 (very small) } \\
\hline & Normative & 3.19 & 0.89 & & & \\
\hline \multirow{2}{*}{ Community } & SASA & 3.40 & 0.78 & \multirow{2}{*}{-0.09 to 0.50} & \multirow{2}{*}{0.600} & \multirow{2}{*}{0.02 (very small) } \\
\hline & Normative & 3.38 & 0.84 & & & \\
\hline \multirow{2}{*}{ Fairness } & SASA & 2.80 & 0.73 & \multirow{2}{*}{-0.09 to 0.51} & \multirow{2}{*}{0.580} & \multirow{2}{*}{0.025 (very small) } \\
\hline & Normative & 2.78 & 0.80 & & & \\
\hline
\end{tabular}

SASA - SASA respondents; Normative - score from the normative study

SD - standard deviation; $95 \% \mathrm{Cl}$ difference - $95 \%$ confidence interval of the difference between the mean values

Low scores $(<3)$ for the various areas of work-life indicate poor congruence between the person and the work environment

Interpretation of Glass's $\Delta: 0=$ no effect; $0.2=$ small effect; $0.5=$ medium effect; $0.8=$ large effect. For the calculation of Glass's $\Delta$, the denominator was the standard deviation of the normative (control) group.

variables. Categorical variables included age-group, gender, sector (private/public), years' experience and professional qualification. A variable entered the model if its associated significance was $p<0.05$ and exited if $p>0.1$. We evaluated goodness of fit by the multiple correlation coefficient and the coefficient of determination, $\left(R^{2}\right)$, adjusted for the number of independent variables in the regression model.

We also performed stepwise logistic regression analysis. The dichotomous, dependent variable was clinically diagnosable burnout (according to the "Emotional Exhaustion+1 principle" ${ }^{5}$ ). Independent variables and criteria for entering the model were the same as the aforementioned for the multiple linear regression analysis. We set the outcome's classification cut-off value to 0.5 . We evaluated the overall model fit by obtaining the difference between the $-2^{*}$ Ln likelihood values for the null and full models which yields a chi-squared statistic. We calculated the coefficient of determination, (pseudo $\mathrm{R}^{2}$ ), according to the method of Nagelkerke. ${ }^{13}$ We evaluated the predictive accuracy of the model by constructing a cross-classifying table. We used the model's predicted probabilities to construct a receiver operating characteristic curve with the dependent variable as the classification variable.

\section{Results}

We received 498 completed questionnaires which represented a response rate of $26.9 \%$ and a margin of error of $3.76 \%$. Cronbach's alpha coefficient for the Area of Worklife Survey (95\% lower confidence limit) was 0.90 (0.91). For the individual AWLs, Cronbach's alpha coefficients were 0.79 (0.77), 0.82 (0.79), 0.89 (0.88), 0.83 (0.81) and 0.81 (0.78) for workload, control, reward, community and fairness respectively. These values exceed the requisite reliability thresholds for research. ${ }^{8}$

The majority of respondents were male (53\%), specialists (76\%) and were in private practice (74\%), of whom $57 \%$ were part of a group practice. There were only 8 intensivists (1.6\%). Public sector respondents worked predominantly (84\%) in academic/ tertiary hospitals.
Table II summarises comparisons of the six AWLs with normative values.

Overall, mean scores returned by the 498 respondents for both workload and control were significantly lower (i.e. more adverse) than normative values (with small effect-sizes). There were no significant differences regarding reward, community and fairness (with small effect-sizes). Regarding the portion of the questionnaire pertaining to the values $A W L$, only 40 in the public sector and 36 in the private sector responded as intended. This was the result of unclear wording in the questionnaire with regard to distinguishing between the organisations within which respondents functioned. Thus, we were unable to evaluate the values AWL appropriately.

Table III and Figure 1 summarise comparisons between the public and private sectors. Public-sector anaesthetists median scores for five AWLs (excluding values) were significantly smaller (i.e. more adverse) than those of private practitioners. The effectsizes for the differences were large for workload and control, medium for reward and small for community and fairness. With regard to the values $\mathrm{AWL}$, the 40 public sector employees as well as the 36 private sector anaesthetists who answered that portion of the questionnaire as intended, revealed greater mismatch between themselves and the hospital administrations for whom they worked, than between themselves and the departments/ practices within which they functioned (with large effect-sizes).

With regard to high, moderate, and low score categories, greater proportions of public sector anaesthetists returned low (i.e. adverse) scores for five AWLs (values excluded). Associated relative risks were high (Figure 1). Accordingly, smaller proportions of public sector anaesthetists had high scores for workload, reward, control and fairness, also with high associated relative risks. We did not detect a significant difference between the proportions of public and private sector anaesthetists who had high scores for fairness.

Table IV summarises the results of the multivariable least squares regression analysis. Explanatory variables for emotional 
Table III: Comparisons of the areas of work-life scores between SASA members working in the public $(n=189)$ and the private sectors $(n=309)$

\begin{tabular}{|c|c|c|c|c|c|c|c|c|}
\hline Area of work-life & Sector & Median score & Score category & IQ range & Range & $95 \% \mathrm{Cl}$ diff & $p$ & Effect size ${ }^{\dagger}$ \\
\hline \multirow{2}{*}{ Workload } & Pub & 2.2 & L & $1.8-2.9$ & $1-4.8$ & \multirow{2}{*}{0.6 to 0.8} & \multirow{2}{*}{$<0.0001$} & \multirow{2}{*}{$\begin{array}{c}0.73 \\
\text { (large) }\end{array}$} \\
\hline & Priv & 3.2 & $M$ & $2.6-3.6$ & $1-5$ & & & \\
\hline \multirow{2}{*}{ Control } & Pub & 2.5 & L & $2.5-2.8$ & $1-4.5$ & \multirow{2}{*}{0.5 to 1} & \multirow{2}{*}{$<0.0001$} & \multirow{2}{*}{$\begin{array}{c}0.73 \\
\text { (large) }\end{array}$} \\
\hline & Priv & 3.5 & M & $3.5-3.8$ & $1.25-5$ & & & \\
\hline \multirow{2}{*}{ Reward } & Pub & 3 & $M$ & $2.3-3.8$ & $1-5$ & \multirow{2}{*}{0.3 to 0.8} & \multirow{2}{*}{$<0.0001$} & \multirow{2}{*}{$\begin{array}{c}0.66 \\
\text { (medium) }\end{array}$} \\
\hline & Priv & 3.5 & M & $3.0-3.4$ & $1-5$ & & & \\
\hline \multirow{2}{*}{ Community } & Pub & 3.4 & $M$ & $2.6-4.0$ & $1-4.8$ & \multirow{2}{*}{0.0 to 0.4} & \multirow{2}{*}{0.002} & \multirow{2}{*}{$\begin{array}{c}0.58 \\
\text { (small) }\end{array}$} \\
\hline & Priv & 3.6 & $M$ & $3.0-4.0$ & $1.2-5$ & & & \\
\hline \multirow{2}{*}{ Fairness } & Pub & 2.7 & $M$ & $2.1-3.0$ & $1-4.5$ & \multirow{2}{*}{0.2 to 0.5} & \multirow{2}{*}{$<0.0001$} & \multirow{2}{*}{$\begin{array}{c}0.62 \\
\text { (small) }\end{array}$} \\
\hline & Priv & 2.8 & $M$ & $2.5-3.5$ & $1.2-5$ & & & \\
\hline \multirow{2}{*}{$\begin{array}{l}\text { Values }^{\ddagger} \\
(n=40)\end{array}$} & Pub (Dept) & 4.0 & $\mathrm{H}$ & $3.5-4.0$ & $2-5$ & \multirow{2}{*}{0.9 to 1.4} & \multirow{2}{*}{$<0.0001$} & \multirow{2}{*}{$\begin{array}{c}0.90 \\
\text { (large) }\end{array}$} \\
\hline & Pub (Hosp) & 2.5 & L & $2.3-3.0$ & $1-5$ & & & \\
\hline \multirow{2}{*}{$\begin{array}{l}\text { Values }^{\ddagger} \\
(n=36)\end{array}$} & Priv (Prac) & 4.3 & $\mathrm{H}$ & $3.8-4.6$ & $2.8-5.0$ & \multirow{2}{*}{1.0 to 1.5} & \multirow{2}{*}{$<0.0001$} & \multirow{2}{*}{$\begin{array}{c}0.97 \\
\text { (large) }\end{array}$} \\
\hline & Priv (Hosp) & 3.0 & $M$ & $2.5-3.1$ & $1.8-4.3$ & & & \\
\hline
\end{tabular}

Pub - Public sector; Priv - Private practice sector

Scores were categorised according to Table I. Low scores indicate poor congruence with the work environment, e.g. a low score for workload implies a high workload job demand.

Codes for score categories: $\mathrm{H}, \mathrm{M}, \mathrm{L}$ - high, moderate and low scores respectively

IQ range - interquartile range

$95 \% \mathrm{Cl}$ diff - 95\% confidence interval of the difference between medians

$P-p$ value generated by Mann-Whitney $U$ test

† Probability of superiority. Interpretation: $0.5=$ no effect; $0.56=$ small effect; $0.64=$ medium effect; $0.71=$ large effect; $0.8=$ very large effect

‡ Wilcoxon signed rank test

Table IV: Results of the stepwise least squares multiple linear regression analysis

\begin{tabular}{|c|c|c|c|c|c|}
\hline Burnout dimension & Independent variables & Coefficient & Standard error & $P^{t}$ & $\mathbf{r}_{\text {partial }}$ \\
\hline \multirow{5}{*}{$\begin{array}{l}\text { Emotional exhaustion } \\
\text { (Adjusted } \mathrm{R}^{2}=0.501 \text { ) }\end{array}$} & Constant & 60.33 & 0.57 & & \\
\hline & Workload & -6.66 & 0.56 & $<0.0001$ & -0.50 \\
\hline & Reward & -2.66 & 0.56 & $<0.0001$ & -0.21 \\
\hline & Community & -2.10 & 0.55 & 0.0003 & -0.16 \\
\hline & Control & -1.58 & 0.52 & 0.0053 & -0.12 \\
\hline \multirow{6}{*}{$\begin{array}{l}\text { Cynicism } \\
\text { (Adjusted R² }=0.252 \text { ) }\end{array}$} & Constant & 22.62 & & & \\
\hline & Workload & -1.71 & 0.31 & $<0.0001$ & -0.24 \\
\hline & Reward & -1.34 & 0.31 & $<0.0001$ & -0.19 \\
\hline & Gender & -1.04 & 0.48 & 0.0325 & -0.10 \\
\hline & Control & -0.84 & 0.33 & 0.0110 & -0.11 \\
\hline & Experience & -0.62 & 0.24 & 0.0086 & -0.12 \\
\hline \multirow{4}{*}{$\begin{array}{l}\text { Efficacy } \\
\text { (Adjusted R }=0.228 \text { ) }\end{array}$} & Reward & 2.02 & 0.42 & $<0.0001$ & 0.21 \\
\hline & Community & 1.43 & 0.44 & 0.0013 & 0.14 \\
\hline & Control & 1.31 & 0.41 & 0.0014 & 0.14 \\
\hline & Experience & 0.81 & 0.30 & 0.0069 & 0.12 \\
\hline
\end{tabular}

Adjusted $\mathrm{R}^{2}$ - the coefficient of determination adjusted for the number of independent variables in the regression model

$r_{\text {partial }}$ - the correlation of the variable with the dependent variable, adjusted for the effect of the other variables in the model

$+P$-value for the Wald chi-squared statistic

exhaustion included workload, reward, community and control. For cynicism they were workload, reward, control, gender and years of experience. Regarding these two burnout dimensions (emotional exhaustion and cynicism), workload and reward were the strongest predictors. Predictors for efficacy included reward, community, control and experience with reward being the strongest predictor.

Note: Low scores for AWLs indicate adverse work settings, hence the negative coefficients regarding emotional exhaustion and cynicism with AWL; conversely positive coefficients for efficacy with AWL.

Table $V$ summarises the results of the logistic regression analysis. Logistic regression identified three AWLS that contributed significantly to the model, namely workload, reward and community. Workload was the strongest predictor, such that reward and community made only minor contributions to the final model. This is demonstrated by the small differences in goodness of fit when workload was the only explanatory variable 
Table V: Parameters of two logistic regression models for a diagnosis of burnout according to the "Emotional Exhaustion+1" principle

\begin{tabular}{|c|c|c|c|}
\hline \multicolumn{4}{|c|}{ Full model } \\
\hline Explanatory variable & Coefficient & $\boldsymbol{P}_{\text {value }}{ }^{+}$ & Odds ratio $(95 \% \mathrm{Cl})$ \\
\hline Constant & 6.290 & $<0.0001$ & \\
\hline Workload & -1.689 & $<0.0001$ & 0.185 (0.121 to 0.281$)$ \\
\hline Reward & -0.590 & 0.0003 & $0.555(0.402$ to 0.765$)$ \\
\hline Community & -0.481 & 0.0098 & 0.618 (0.429 to 0.891$)$ \\
\hline \multicolumn{4}{|c|}{ Reduced model } \\
\hline Explanatory variable & Coefficient & $\boldsymbol{P}_{\text {value }}{ }^{\dagger}$ & Odds ratio $(95 \% \mathrm{Cl})$ \\
\hline Constant & 3.501 & $<0.0001$ & \\
\hline Workload & -1.906 & $<0.0001$ & $0.149(0.100$ to 0.222$)$ \\
\hline
\end{tabular}

(Table V and Table A1 in the Appendix). Both models classified $>80 \%$ of cases correctly.

\section{Discussion}

Whereas congruence between the worker and the six AWLs promote work engagement, mismatches in a few crucial areas can result in distress and the risk of burnout. ${ }^{2}$ The ideal working environment should involve manageable workloads, where employees are treated fairly and respectfully (fairness, reward and values AWLs) and where they are permitted to make meaningful decisions about their work (control, values). People should be recognised for their efforts by the organisation and by their colleagues (reward, community) and they should feel comfortable about their job and with their co-workers (community, values). Figure 2 portrays a model of the complex interrelations between the six AWLs and the three burnout dimensions. ${ }^{4,14}$

The central and right-hand sections of Figure 2 depict how the three dimensions of the Maslach burnout model influence the outcome of a person's psychological relationship with his/her work. This outcome can be regarded as taking place somewhere on a continuous scale, one extreme being burned out (emotionally exhausted, detached and ineffective) and the other being engagement (a state of high energy, strong involvement and effectiveness). ${ }^{15}$ The central section of Figure 2 also illustrates how energy depletion (i.e. emotional exhaustion) progresses to decreased involvement (cynicism or depersonalisation), which is an initial defence mechanism, and subsequently to feelings of futility (decreased efficacy or personal accomplishment). The left-hand section of the AWLS model depicts the important role played by workload. Workload impacts directly on the energy dimension of burnout, which in turn influences involvement and efficacy. Control, by enabling choices that impact important work-life decisions, is central to the model. The pivotal role of these two AWLs are supported by the demand-control job-stress theory, ${ }^{16}$ whereby distress results from excessive workloads together with inability to participate in decision making. The AWLs model expands the demandcontrol job-stress theory, whereby values plays an integrative role, by mediating all three burnout dimensions. Values in turn are influenced by rewards, community and fairness. Thus, workers' values are likely to be congruent with those of the organisation if they feel that the organisation enables them to participate in work-related decisions, that they are treated fairly and equitably

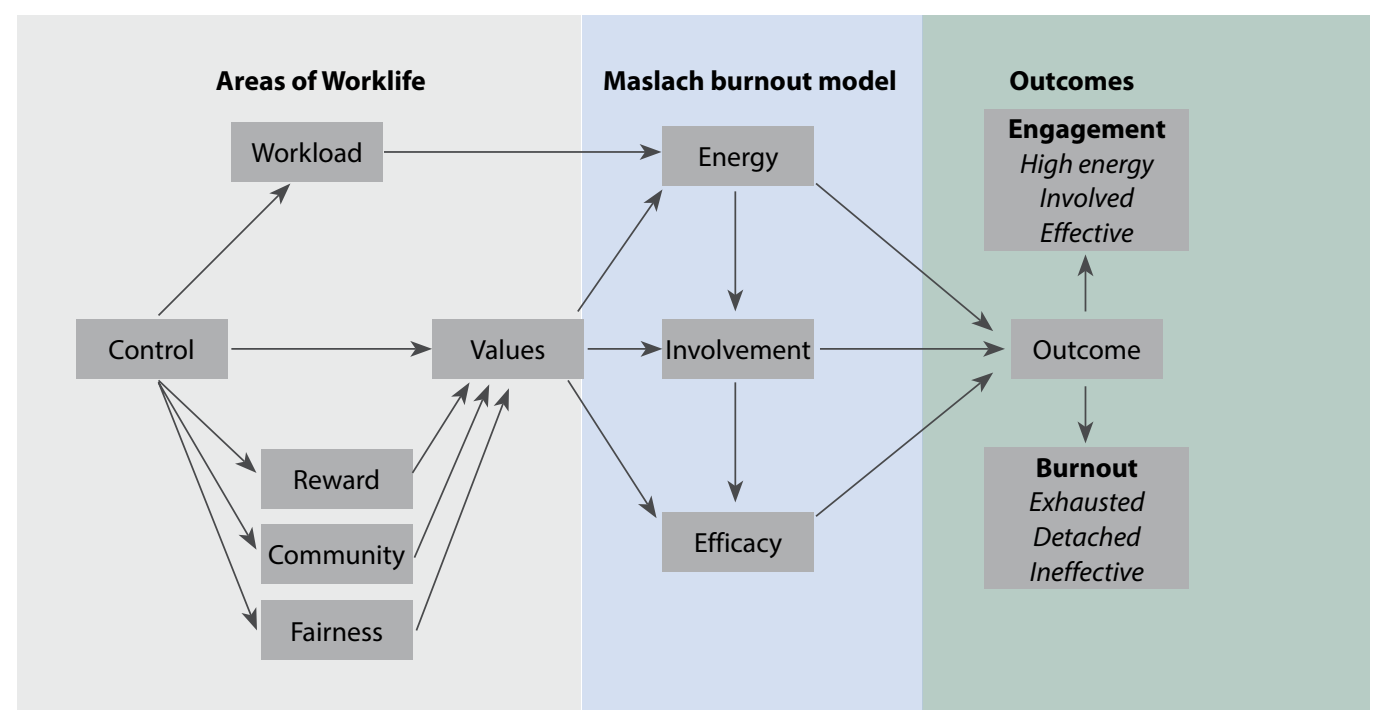

Figure 2: The interrelations between the AWLs and the three burnout dimensions Adapted from Gascon et al. ${ }^{14}$ 
by the organisation and by colleagues who are supportive and appreciative of their efforts. A deficiency of any one of these AWLS is likely to result in a conflict with personal values, increasing the risk of burnout. ${ }^{4,14}$

Our regression models highlight the dominant role of an excessive workload among our respondents. The central position of control is confirmed, being associated with all three burnout dimensions. The mediating roles of reward and community also feature in the models. The non-inclusion of fairness into the regression models indicates perhaps that generally, anaesthetists perceive that they are treated without favouritism. It is a weakness that we could not incorporate the values AWL into our analysis; however, there appears to be a group of anaesthetists (notably in the public sector) who experience conflict between their core values and the value systems of their employers.

Work overload and lack of control over professional life appear to be the main driving forces towards burnout with inputs from the reward and community AWLs. The coefficient of determination for the full logistic regression model was 0.448 signifying that $44.8 \%$ of the variability could be explained by the model. Other socio-demographic characteristics also contribute to the risk of burnout. We found a greater prevalence among younger participants with less than 15 years' experience. Personality type, which we did not evaluate, also contributes to the development of the syndrome. The "Big Five" model of personality traits comprise neuroticism, extroversion, openness to experience, conscientiousness and agreeableness. ${ }^{17}$ In a study regarding personality traits and burnout among 655 Dutch anaesthetists, Van der Wal and colleagues ${ }^{18}$ concluded that neuroticism was the most important predictor of burnout, while extroversion and openness were protective.

The overall purpose of this study was to determine the prevalence and degree of burnout and to broadly identify possible causative factors. We cannot speculate about solutions to the problem, other than to draw attention to systematic reviews ${ }^{15,19-22}$ that conclude that changes within organisations are more effective than individual approaches, such as improving resilience, Balint groups, mindfulness exercises, etc. Considering that previous studies among state-employed South African doctors have also demonstrated disturbing levels of burnout, ${ }^{23-26}$ it is imperative that our various professional societies and associations confront the national and provincial departments of health with the purpose of addressing the root causes of physician burnout. Doctors working within an authoritarian system, being subjected to unreasonable workloads and demands that conflict with their personal core values, who are emotionally exhausted, detached, cynical and who perceive themselves as ineffective, are not likely to deliver efficient, patient-orientated healthcare. The words of Dinesh Bhugra‡ ring true: "A system that fails to support and protect the health of its own workforce will only flounder, and this is as clear a call to action if ever there was one."27

\section{Acknowledgements}

Mr Dawid van Straaten for transcribing the questionnaires to the REDCap system and for his persistence in spite of an erratic email server.

Professor Andrew Levin for his helpful improvements to the manuscript text.

\section{Conflict of interest}

The authors declare no conflict of interest.

\section{Funding source}

The SASA Jan Pretorius Research Fund funded licences for the questionnaires.

\section{Ethics approval}

The Stellenbosch University Research Ethics Committee, Humanities, granted approval to conduct this anonymised prospective, analytic, cross-sectional study (Project No.6254)

\section{ORCID}

JF Coetzee (iD) https://orcid.org/0000-0002-9925-7767 H Kluyts (iD https://orcid.org/0000-0002-9917-1330

\section{References}

1. Coetzee JF, Kluyts $\mathrm{H}$. Burnout and areas of work-life among anaesthetists in South Africa Part 1: Burnout. Southern African J Anaesth Analg 2020;26(2):73-82. https://doi.org/10.36303/SAJAA.2020.26.2.2358

2. Leiter MP, Gascón S, Martínez-Jarreta B. Making sense of work life: a structural model of burnout. J Appl Soc Psychol. 2010;40(1):57-75. https://doi. org/10.1111/j.1559-1816.2009.00563.x

3. Leiter MP, Maslach C. Areas of Worklife Survey Manual and Sampler Set. 5th ed. Menlo Park, CA: Mind Garden Inc.; 2011.

4. Leiter MP, Shaughnessy K. The areas of worklife model of burnout: tests of mediation relationships. Ergonomia: An International Journal. 2006;28:327-41.

5. Brenninkmeijer V, VanYperen $\mathrm{N}$. How to conduct research on burnout: advantages and disadvantages of a unidimensional approach in burnout research. Occup Environ Med. 2003 Jun;60 Suppl 1:i16-20. https://doi. org/10.1136/oem.60.suppl_1.i16.

6. MedCalc Statistical Software. 18.11 ed. Ostend, Belgium: MedCalc Software bvba; 2018.

7. Bryant T. Confidence Interval Analysis. 2.20 Build 57 ed: University of Southampton; 2011.

8. Bland JM, Altman DG. Cronbach's alpha. BMJ (Clinical research ed). 1997 Feb 22;314(7080):572. https://doi.org/10.1136/bmj.314.7080.572.

9. Cronbach LJ. Coefficient alpha and the internal structure of tests. Psychometrika. 1951;16(3):297-334. https://doi.org/10.1007/BF02310555.

10. Altman DG, Machin D, Bryant TN, Gardner MJ. Statistics with confidence. 2nd ed. Bristol: BMJ Books; 2000

11. Conover WJ. Practical non-parametric statistics. 3rd ed. New York: John Wiley; 1999.

12. Ellis PD. The essential guide to effect sizes. New York: Cambridge University Press; 2010.

13. Nagelkerke NJD. A note on a general definition of the coefficient of determination. Biometrika. 1991;78(3):691-2. https://doi.org/10.1093/ biomet/78.3.691.

14. Gascón S, Leiter MP, Stright N, et al. A factor confirmation and convergent validity of the "areas of worklife scale" (AWS) to Spanish translation. Health Qua Life Outcomes. 2013 Apr 18;11:63. https://doi.org/10.1186/1477-7525-11-63.

15. Shanafelt TD, Noseworthy JH. Executive leadership and physician well-being nine organizational strategies to promote engagement and reduce burnout. Mayo Clin Proc. 2017 Jan;92(1):129-46. https://doi.org/10.1016/j. mayocp.2016.10.004.

16. Karasek $\mathrm{R}$, Theorell $\mathrm{T}$. Healthy work: stress, productivity, and the reconstruction of working life. Michigan: Basic Books; 1990.

17. McCrae RR, Costa PT. Validation of the five-factor model of personality across instruments and observers. J Pers Soc Psychol. 1987:52(1):81.

18. Van der Wal RAB, Bucx MJL, Hendriks JCM, Scheffer G-J, Prins JB. Psychological distress, burnout and personality traits in Dutch anaesthetists: A survey. 
Eur J Anaesthesiol. 2016 Mar;33(3):179-86. https://doi.org/10.1097/ EJA.0000000000000375.

19. Busireddy KR, Miller JA, Ellison K, et al. Efficacy of interventions to reduce resident physician burnout: a systematic review. J Grad Med Educ. 2017 Jun;9(3):294-301. https://doi.org/10.4300/JGME-D-16-00372.1.

20. Panagioti M, Panagopoulou E, Bower $P$, et al. Controlled interventions to reduce burnout in physicians: a systematic review and meta-analysis. JAMA Intern Med. 2017 Feb 1;177(2):195-205. https://doi.org/10.1001/jamainternmed.2016.7674.

21. Rothenberger DA. Physician burnout and well-being: a systematic review and framework for action. Diseases of the Colon \& Rectum. 2017 Jun;60(6):567-76. https://doi.org/10.1097/DCR.0000000000000844.

22. West $C P$, Dyrbye LN, Erwin PJ, Shanafelt TD. Interventions to prevent and reduce physician burnout: a systematic review and meta-analysis. Lancet. 2016 Nov 05;388(10057):2272-81. https://doi.org/10.1016/S0140-6736(16)31279-X.

23. Liebenberg AR, Coetzee FJ, Conradie HH, Coetzee JF. Burnout among rural hospital doctors in the Western Cape: comparison with previous South

\section{Appendix}

\section{Definitions of the six areas of work-life (verbatim quote from Leiter and Maslach) ${ }^{3}$}

\section{Workload}

"The most obvious, and most commonly discussed, source of burnout is a heavy workload, when job demands exceed human limits. People have to do too much in too little time with too few resources. Increasing workload has a consistent relationship with burnout, especially with the exhaustion dimension."

\section{Control}

"This area includes employees' perceived capacity to influence decisions that affect their work, to exercise professional autonomy, and to gain access to the resources necessary to do an effective job."

\section{Reward}

"The reward area of worklife addresses the extent to which rewards - monetary, social, and intrinsic - are consistent with expectations. Lack of recognition from service recipients, colleagues, managers, and external stakeholders devalues both the work and the workers and is closely associated with feelings of inefficacy."

\section{Community}

"Community is the overall quality of social interaction at work, including issues of conflict, mutual support, closeness, and the capacity to work as a team."

\section{Fairness}

"Fairness is the extent to which decisions at work are perceived as being fair and people are treated with respect."
African studies. Afr J Prm Health Care Fam Med. 2018;10(1):a1568. https://doi org/10.4102/phcfm.v10i1.1568.

24. Peltzer K, Mashego T-A, Mabeba M. Short communication: Occupational stress and burnout among South African medical practitioners. Stress Health 2003;19(5):275-80. https://doi.org/10.1002/smi.982.

25. Rossouw L, Seedat S, Emsley RA, Suliman S, Hagemeister D. The prevalence of burnout and depression in medical doctors working in the Cape Town Metropolitan Municipality community healthcare clinics and district hospitals of the Provincial Government of the Western Cape: a cross-sectional study. S Af Fam Pract. 2013;55(6):567-73. https://doi.org/10.1080/20786204.2013.10874418.

26. Stodel JM, Stewart-Smith A. The influence of burnout on skills retention of junior doctors at Red Cross War Memorial Children's Hospital: a case study. S Afr Med J. 2011 Feb;101(2):115-8. https://doi.org/10.7196/SAMJ.4431.

27. Bhugra D. Serious mental health crisis among doctors and medical students revealed in BMA report. London: British Medical Association; 2019; Available from: https://www.bma.org.uk/news/media-centre/press-releases/2019/may/ serious-mental-health-crisis-among-doctors-and-medical-students-revealedinbma-report.

\section{Values}

"The values area is at the heart of people's relationship with their work. It encompasses the ideals and motivations that originally attracted them to the job.[...] However, when there is a values conflict on the job, it can undermine people's engagement with work. The greater the gap between individual and organisational values, the more often staff members find themselves making a trade-off between work they want to do and work they have to do."

Table A1: Evaluation of the goodness of fit of two logistic regression models for a diagnosis of burnout according to the "Emotional Exhaustion +1 " principle ${ }^{5}$

\begin{tabular}{|c|c|c|}
\hline \multirow{2}{*}{ Statistic } & \multicolumn{2}{|c|}{ Explanatory variables } \\
\hline & Full model & Workload only \\
\hline Chi-squared; p-value & $173.5 ; p<0.0001$ & $137.8 ; p<0.0001$ \\
\hline Pseudo $\mathrm{R}^{2}$ & 0.448 & 0.368 \\
\hline C-statistic & 0.87 (0.84 to 0.90$)$ & 0.84 (0.81 to 0.87 ) \\
\hline \multicolumn{3}{|c|}{ Proportions of cases correctly classified } \\
\hline & Full model & Workload only \\
\hline Total sample $(n=498)$ & $\begin{array}{c}83.7 \% \\
(80.2 \text { to } 86.7)\end{array}$ & $\begin{array}{c}80.9 \% \\
(77.2 \% \text { to } 84.1 \%)\end{array}$ \\
\hline Not clinically burned out & $\begin{array}{c}93.3 \% \\
(90.3 \% \text { to } 95.4 \%)\end{array}$ & $\begin{array}{c}90.9 \% \\
(87.6 \% \text { to } 93.4 \%)\end{array}$ \\
\hline Clinically burned out & $\begin{array}{c}51.3 \% \\
(42.2 \% \text { to } 60.3 \%)\end{array}$ & $\begin{array}{c}49.9 \% \\
(38.0 \% \text { to } 56.1 \%)\end{array}$ \\
\hline \multicolumn{3}{|c|}{$\begin{array}{l}\text { Proportions are } \% \text { ( } 95 \% \text { confidence interval) } \\
\text { The full model comprised the workload, reward and community areas of work-life scores as } \\
\text { explanatory variables. In the workload only model, only workload scores were included as } \\
\text { the explanatory variable. } \\
\text { Pseudo } R^{2} \text { : Nagelkerke coefficient of determination }{ }^{13} \\
\text { C-statistic - area under the receiver operating characteristic curve }\end{array}$} \\
\hline
\end{tabular}

